\title{
Identification of Immunodominant Epitopes of Schistosoma mansoni Vaccine Candidate Antigens Using Human T Cells
}

\author{
CT Fonseca, E Cunha-Neto*, J Kalil*, AR de Jesus**, R Correa-O liveira***, \\ EM Carvalho**, SC O liveira/ ${ }^{+}$
}

\begin{abstract}
Departmento de Bioquímica e Imunologia, Instituto de Investigação em Imunologia-Instituto do Milênio, Universidade Federal de Minas Gerais, Av. Antonio Carlos 6627, 31270-901 Belo Horizonte, MG, Brasil *Laboratorio de Imunologia, Instituto do Coração, Universidade de São Paulo, São Paulo, SP, Brasil **Servico de Imunologia, Hospital Universitario Professor Edgard Santos, Universidade Federal da Bahia, Salvador, BA, Brasil ***Laboratorio de Imunologia, Centro de Pesquisas Rene Rachou-

Fiocruz, Belo Horizonte, MG, Brasil
\end{abstract}

Paramyosin and Sm14 are two of the six antigens selected by the World Health Organization as candidates to compose a subunit vaccine against schistosomiasis. Both antigens are recognized by individuals naturally resistant to Schistosoma mansoni infection and induced protective immunity in the murine model. Three Sm14 epitopes and eleven paramyosin epitopes were selected by their ability to bind to different HLA-DR molecules using the TEPITOPE computer program, and these peptides were synthetically produced. The cellular recognition of $S m 14$ and paramyosin epitopes by peripheral blood mononuclear cells of individuals living in endemic area for schistosomiasis was tested by T cell proliferation assay. Among all Sm14 and paramyosin epitopes studied, Sm14-3 was preferentially recognized by individuals naturally resistant to S. mansoni infection while Para-5 was preferentially recognized by individuals resistant to reinfection. These two peptides represent promising antigens to be used in an experimental vaccine against schistosomiasis, since their preferential recognition by resistant individuals suggest their involvement in the induction of protective immunity.

Key words: T cells - synthetic peptides - vaccines - Schistosoma mansoni - Sm14 - paramyosin

Schistosomiasis is an important parasitic disease, which affects more than 200 million people in 74 countries around the world and causes approximately 20,000 death per year (Bergquist 2002). Currently, schistosomiasis control strategy is mainly based on the treatment of infected individuals by chemotherapy with safe and effective drugs (Harder 2002). In spite of two decades of chemotherapy, the number of infected people remains almost the same (Bergquist 1998). Therefore, vaccination as a way to control schistosomiasis would contribute enormously to disease eradication, mainly because immunization provides long-lasting immunity to the disease.

Among schistosome proteins tested as immunogens in experimental immunization protocols, Sm14 and paramyosin are two promising molecules to compose a subunit vaccine against schistosomiasis (Bergquist 1995). Paramyosin or Sm97 is a myofibrillar protein of $97 \mathrm{kDa}$ located in the muscles and tegument of schistosome worms (Pearce et al. 1988). Both cellular and humoral immune responses are important mechanisms in the protective immunity induced by paramyosin immunization. Passive transfer of monoclonal antibody against paramyosin to

Financial support: CNPq, Fapesp, Fapemig

${ }^{+}$Corresponding author. Fax: +55-31-3499.2666. E-mail: scozeus@icb.ufmg.br

Received 28 May 2004

Accepted 26 July 2004 naive mice, in an early stage of the challenge infection, results in partial but significant reduction in worm burden (Lanar et al. 1986). Also, immunization with recombinant or purified paramyosin induces significant level of protection, which involves interferon- $\gamma($ IFN- $\gamma$ ) production by stimulated T cells (Pearce et al. 1988). Studies of the human immune response to paramyosin support the potential use of this protein as a vaccine candidate, since $S$. mansoni paramyosin is strongly recognized by sera of individuals naturally resistant to parasite infection (Correa-Oliveira et al. 1989) and induces the production of high levels of IFN- $\gamma$ by peripheral blood mononuclear cells (PBMCs) of these individuals (Ribeiro de Jesus et al. 2000).

Regarding Sm14, it is a $14 \mathrm{kDa} S$. mansoni fatty acidbinding protein involved in fatty acid trafficking (Moser et al. 1991). Immunization of mice with rSm14 induces partial protection that is increased by the use of the recombinant form of interleukin (IL-12) as adjuvant. Both immunization protocols induce a Th1 cytokine profile with high IFN- $\gamma$ production and low IL- 4 . The protective immunity induced by rSm14/rIL-12 immunization is dependent on endogenous IFN- $\gamma$ and tumor necrosis factor- $\alpha$ (TNF- $\alpha$ ), since mice deficient on IFN- $\gamma$ and TNFR p55 genes are not able to mount a protective response when submitted to this vaccination protocol (Fonseca et al. 2004). Furthermore, another study performed by our group demonstrated that CD4+ $\mathrm{T}$ cells from naturally resistant individuals living in an endemic area of schistosomiasis, mounted a Th1-type of immune response to $\mathrm{rSm} 14$ based on IFN- $\gamma$ and TNF- $\alpha$ production (Brito et al. 2000a). Moreover, $\mathrm{T}$ cell proliferative responses from these individuals to rSm14 are totally abrogated when these cells were treated with anti-IFN- $\gamma$ antibodies. This result demonstrates that 
$\mathrm{T}$ cell activation to $\mathrm{rSm} 14$ in these individuals, who are the model for natural resistance to human schistosomiasis, is dependent on IFN- $\gamma$ suggesting a role for human Th1 pattern of immune response in the control of this parasitic disease.

Modern vaccines should contain epitopes able to induce protective response in the majority of the population, therefore it turns relevant to study which schistosome antigen epitopes are recognized by human T cells. Here, we report the cellular recognition by PBMCs of individuals living in endemic area for schistosomiasis in response to Sm14 and paramyosin synthetic peptides selected using the TEPITOPE algorithm, that can predict peptide binding to multiple HLA-DR molecules.

\section{MATERIALS AND METHODS}

Patients - Heparinized peripheral blood was obtained from individuals living in an endemic area for schistosomiasis; these individuals were classified in four groups regarding their infection status. These groups were, infected (INF), resistant to reinfection (RR), susceptible to reinfection (SR), and naturally resistant (NR) individuals. Details regarding sex, age, classification parameters are described in the Table. These patients or their legal guardians gave informed consent after explanation of the protocol that had been previously approved by the Ethical Committee of the Federal University of Minas Gerais.

Antigen preparation - SWAP (soluble adult worm antigen preparation) was prepared as previously described (Colley et al. 1977). Recombinant Sm14 was produced using the pMal-c2 expression system as previously described (Brito et al. 2000b). Protein concentration was determined according to Bradford's method (1976).

Synthetic peptides - 17 or 18-mer synthetic peptides containing epitopes of Sm14 and paramyosin selected using the TEPITOPE algorithm computer program, were purchased from Mimotope (San Diego, CA, US). All 1718 mer peptides were synthetically produced by solidphase method and were purified by high-performance liquid chromatography.

$T$ cell proliferation assay - PBMC were isolated from peripheral blood by Ficoll-Hypaque density gradient centrifugation $(\mathrm{d}=1.077)$, washed three times with sterile saline, and incubated in RPMI 1640 medium (Gibco) supplemented with $10 \%$ of normal human AB serum (Sigma, St. Louis, MO), $100 \mathrm{U} / \mathrm{ml}$ of penicillin $\mathrm{G}$ sodium, $100 \mathrm{mg} / \mathrm{ml}$ of streptomycin sulfate, $250 \mathrm{ng} / \mathrm{ml}$ of amphatericin B. In proliferation assay, cells cultures from PBMC from studied individuals were carried out in triplicate in 96-well-flatbottom culture plates $\left(10^{5}\right.$ cells/well; final volume $\left.0.2 \mathrm{ml}\right)$ with recombinant Sm14 (50 $\mu \mathrm{g} / \mathrm{ml}), \operatorname{SWAP}(25 \mu \mathrm{g} / \mathrm{ml}), \operatorname{Sm} 14$ peptides $(50 \mu \mathrm{M})$ and paramyosin peptides $(10 \mu \mathrm{M})$. Phytohaemaglutinin (PHA) $(2 \mu \mathrm{g} / \mathrm{ml}$ ) was used as positive control and unstimulated culture was used as negative control. Plates were incubated in $5 \% \mathrm{CO}_{2}$ at $37^{\circ} \mathrm{C}$ for five days and cultures were pulsed with $0.5 \mu \mathrm{Ci} /$ well $\left[{ }^{3} \mathrm{H}\right]$ thymidine (Amersham Bioscience, Sydney, Australia) for $18 \mathrm{~h} .\left[{ }^{3} \mathrm{H}\right]$-thymidine incorporation was measured using a Beta Counter apparatus (Packard, IL). Data are represented as proliferation index (PI) defined as mean cpm experimental triplicates with antigen/mean cpm of triplicates of culture medium control. PI values $\geq 2.0$ were considered positive.

Statistic analysis - Mann-Whitney's rank sum test was used to compare continuous variables in T cell proliferation assays.

\section{RESULTS}

$T$ cell epitope prediction - Fig. 1 shows the result of TEPITOPE analysis of the amino acid sequence of Sm14 and paramyosin at 3\% threshold. Promiscuous Sm14 epitopes are observed in the N-terminal region of the protein while paramyosin promiscuous epitopes are distributed throughout the entire amino acid sequence of this antigen (data not shown). Three Sm14 epitopes were selected by their ability to bind with high affinity to several HLA-DR molecules used in TEPITOPE analysis: Sm14-1 (1-18) MSSFLGKWKLSESHNFDA; Sm14-2 (32-48) IGNTVTPTVTFTMDGDK and Sm14-3 (53-69) TES TFKNISCTFKFGEE. Sm14-1 was the most promiscuous epitope able to bind to 10/25 HLA-DR molecules followed by Sm14-3 and Sm14-2 (Fig. 1). Eleven paramyosin epitopes were selected by TEPITOPE analysis: Para-1 (6-20) TESHVKISRTIYRGVSP; Para-2 (13-29) SRTIYR GVSPSTTRLES; Para-3 (151-167) LDGALKAKQSA ESKLEG; Para-4 (168-184)LDSQLNRLKSLTDDLQR; Para-

TABLE

Study population

\begin{tabular}{|c|c|c|c|c|}
\hline Group & Infection status & Description & $\begin{array}{c}\text { Age } \\
(\text { mean } \pm \text { SD) }\end{array}$ & $\begin{array}{l}\text { Sex } \\
\text { le/female) }\end{array}$ \\
\hline $\begin{array}{l}\text { Natural resistant } \\
(\mathrm{NR}) \mathrm{n}=11\end{array}$ & Not infected & $\begin{array}{l}\text { Individuals living in an endemic area for schistosomiasis that } \\
\text { although water contact, present stool negative examination }\end{array}$ & $52,63 \pm 9,96$ & $5 / 6$ \\
\hline $\begin{array}{l}\text { Resistant to } \\
\text { reinfection } \\
(\mathrm{RR}) \mathrm{n}=8\end{array}$ & Not infected & $\begin{array}{l}\text { Individuals living in an endemic area for schistosomiasis that } \\
\text { although water contact, present stool negative examination } \\
\text { after praziquantel treatment }\end{array}$ & $26,8 \pm 25,5$ & $2 / 6$ \\
\hline $\begin{array}{l}\text { Susceptible to } \\
\text { reinfection } \\
(\mathrm{SR}) \mathrm{n}=13\end{array}$ & $\begin{array}{l}\text { Schistosoma } \\
\text { mansoni }\end{array}$ & $\begin{array}{l}\text { Individuals living in an endemic area for schistosomiasis that } \\
\text { present stool positive examination after praziquantel } \\
\text { treatment }\end{array}$ & $22,9 \pm 17,7$ & $5 / 8$ \\
\hline $\begin{array}{l}\text { Infected } \\
(\text { INF) } \mathrm{n}=16\end{array}$ & S. mansoni & $\begin{array}{l}\text { Individuals living in an endemic area for schistosomiasis with } \\
\text { stool positive examination }\end{array}$ & $27,61 \pm 17,46$ & $6 / 10$ \\
\hline
\end{tabular}


5 (210-226) YEAQILNYSKAKSSLES; Para-6 (355-371) NSELIRRAKAAESLASD; Para-7 (399-415) RLKSLVNDLT DKNNLLE; Para-8 (584-600) AENNLQITEHKRLQLAN; Para-9 (676-692) NNEVLRLADELRQEQGN; Para-10 (760776) FERQYKELQTQAEDDRR; Para-11 (830-846) AERTVTVRRVGPGGRAV. Among paramyosin epitopes, Para-6 is the most promiscuous epitope able to bind 6/25 HLA-DR molecules according to TEPITOPE analysis, followed by Para-5, Para-1, Para-4, Para-9, Para-2, Para-7, Para11, Para-3, Para-8 and Para-10 (Fig. 1).

Proliferative responses to synthetic peptides. The purified synthetic peptides were used as antigens in cell proliferation assays using PBMCs of individuals living in endemic area for schistosomiasis to test human $\mathrm{T}$ cell recognition of Sm14 and paramyosin epitopes. In order to select peptides that could be recognized by resistant versus susceptible individuals, we compared the proliferation index of the NR group versus INF individuals, and

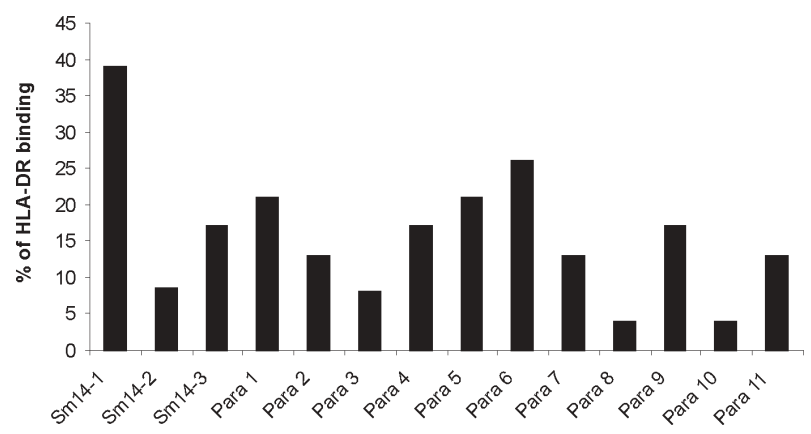

Fig. 1: number of HLA class II molecules that binds to Sm14 and paramyosin peptides at $3 \%$ threshold.

A

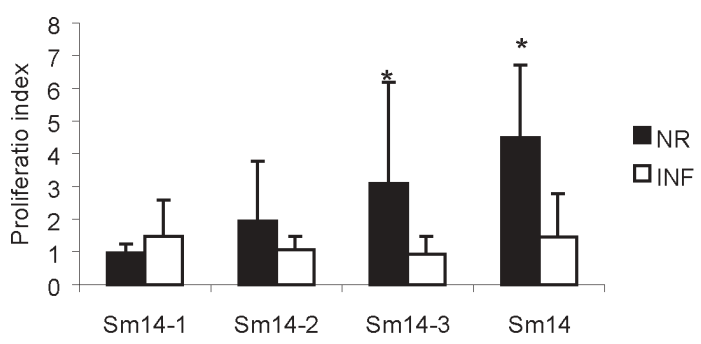

C

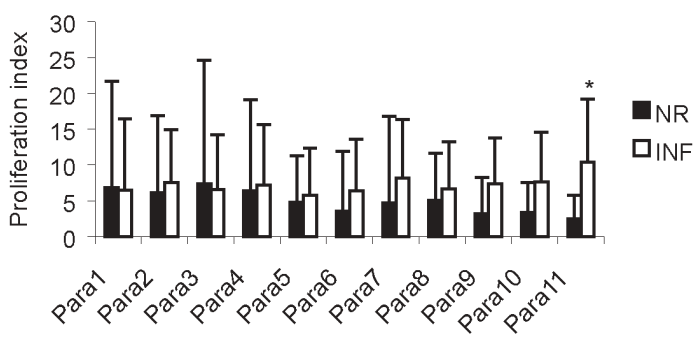

RR patients versus the SR group. Among Sm14 peptides, Sm14-3 is the epitope preferentially recognized by PBMCs of individuals naturally resistant to $S$. mansoni infection compared to infected patients (Fig. 2A). Recombinant Sm14 is also recognized by PBMCs of NR individuals. Paramyosin synthetic peptides are recognized by a higher number of individuals living in endemic area for schistosomiasis (Fig. 2C, D). However, Para-5 is preferentially recognized by PBMCs of individuals resistant to $S$. mansoni reinfection (Fig. 2D), while Para-11 is preferentially recognized by PBMCs of infected individuals (Fig. 2C).

\section{DISCUSSION}

The development of vaccines for complex parasites, such as $S$. mansoni, is a great challenge. Given the persistent lack of an effective immunogen, several vaccine development strategies have been tried, such as the use of synthetic peptides. The amino acid sequence of most schistosome vaccine antigens shows several identical residues with the mammalian counterpart. Immunization with the whole parasite protein or conserved regions of the molecule may potentially induce autoimmune responses. Therefore, it is important to select the least conserved peptides of schistosome antigens, such as Sm14 and paramyosin, to be used in a vaccine formulation. In a recent study performed in an endemic area for schistosomiasis in Egypt, cellular immune response to Sm14 and paramyosin was related with resistance to reinfection (Al-Sherbiny et al. 2003). These findings reinforce the importance of identifying $\mathrm{T}$ cell epitopes on these antigens that may be involved in the induction of protective immunity.
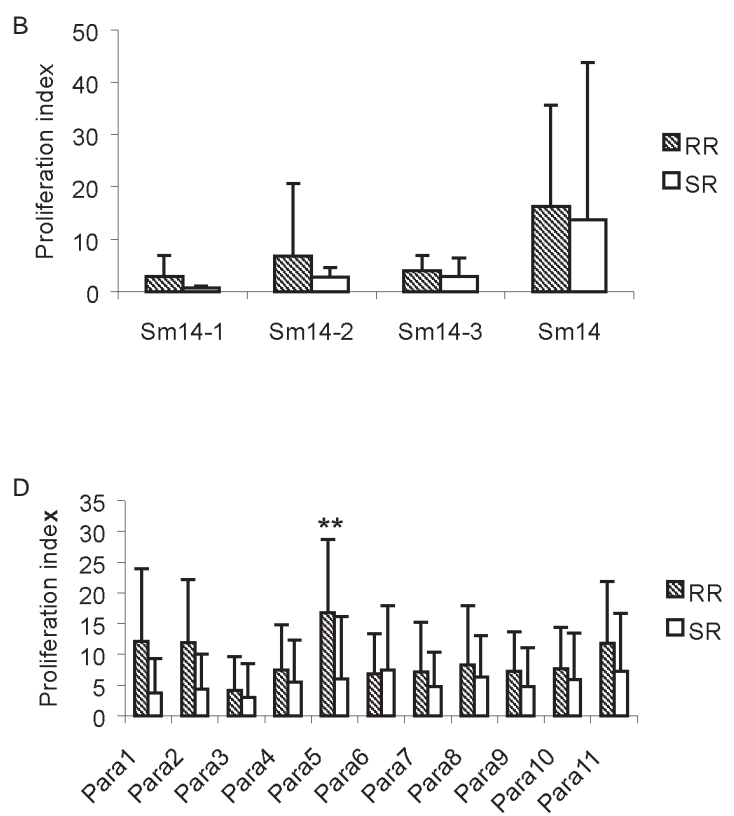

Fig. 2: proliferative responses to recombinant Sm14 and Sm14 peptides (A and B) or paramyosin peptides (C and D) of peripheral blood mononuclear cells from individuals naturally resistant to Schistosoma mansoni infection (NR), infected individuals (INF), individuals resistant to reinfection (RR), and susceptible to reinfection (SR). Bars represent the mean of proliferation index (cpm of stimulated cultures/cpm of unstimulated cultures) \pm standard deviation (SD). Statistically significant differences $(P<0.05)$ between NR vs INF group are denoted by an asterisk and between RR vs SR group by two asterisks. 
Herein, we used the TEPITOPE computer program that is a matrix-based algorithm that predicts binding to 25 distinct HLA-DR molecules. This program allows potential selection of high affinity-binding peptides in Sm14 and paramyosin, those with the highest chance of eliciting an effective T cell response. Exogenous peptides bearing T-cells epitopes prime the immune system probably by binding to empty MHC molecules present on the surface of antigen-presenting cells. However, a single epitope defined in a host of a particular MHC type may therefore be an inadequate substitute for intact antigen in an outbred population that means that multiple and different $\mathrm{T}$ cell epitopes are needed for an effective vaccine. The majority of the studies defining T-cell epitopes in schistosome protective antigens have used the animal model to screen these synthetic peptides. Here, we have tested peptides using human T-cells from resistant and susceptible individuals living in an endemic area for schistosomiasis.

Synthetic peptides as vaccine candidates have several advantages, they are easy to produce and high quantities of a homogeneous product may be obtained while avoiding complicated purification procedures of recombinant protein vaccines. Another advantage is that T-cell and B-cell epitopes may be selected. Lately, immuodominants epitopes of others $S$. mansoni antigens have also been identified and successfully used as antigens in immunization protocols. A B-cell epitope of 9B antigen, peptides from SG3PDH or from Sm-37-GAPDH together with Sm-10-DLC were able to induce partial protective immunity in the murine model (Tarrab-Hazdai et al. 1998, Argiro et al. 2000, Tallima et al. 2003). Regarding Sm14 and paramyosin, only B-cell epitopes, different from the peptides described in this study, have been previously identified (Nara et al. 1997, Vilar et al. 2003).

In conclusion, our study identified two peptides, Sm143 and Para-5, as promising epitopes to compose an antischistosomiasis vaccine. These peptides are preferentially recognized by PBMCs of resistant individuals and might be involved in the induction of antigen-specific resistance to human schistosomiasis. Our long term research goal is to assemble multivalent constructs containing schistosome B- and T-cell epitopes recognized by resistant individuals living in an endemic area for schistosomiasis and test them for protective immunity in mice. In this approach, synthetic genes coding for amino acid sequence of epitopes from various antigens are going to be inserted into a DNA vaccine vector for mammalian expression.

\section{REFERENCES}

Agiro L, Henri S, Dessein H, Kouriba B, Dessein AJ, Bourgois A 2000. Induction of protection against $S$. mansoni with a MAP containing epitopes of Sm37-GAPDH and Sm10DLC. Effect of coadsorbtion with GM-CSF on alum. Vaccine 18: 2033-2038.

Al-Sherbiny M, Osman A, Barakat R, El Morshedy H, Bergquit $\mathrm{R}$, Olds R 2003. In vitro cellular and humoral responses to Schistosoma mansoni vaccine candidate antigens. Acta Trop 88: 117-130.

Bergquist NR 1995. Schistosomiasis vaccine development: approaches and prospects. Mem Inst Oswaldo Cruz, 90: 221227.
Bergquist NR 1998. Schistosomiasis vaccine development: progress and prospects. Mem Inst Oswaldo Cruz 93: 95101.

Bergquist NR 2002. Schistosomiasis: from risk assessment to control. Trends Parasitol 18: 309-314.

Bradford MM 1976. A rapid and sensitive method for the quantitation of microgram quantities of protein utilizing the principle of protein-dye binding. Anal Biochem 72: 248254.

Brito CF, Caldas IR, Coura Filho P, Correa-Oliveira R, Oliveira SC 2000a. CD4+ T cells of schistosomiasis naturally resistant individuals living in an endemic area produce interferon-gamma and tumour necrosis factor-alpha in response to the recombinant $14 \mathrm{kDa}$ Schistosoma mansoni fatty acidbinding protein. Scand J Immunol 51: 595-601.

Brito CF, Fonseca CT, Goes AM, Azevedo V, Simpson AJ, Oliveira SC 2000b. Human IgG1 and IgG3 recognition of Schistosoma mansoni $14 \mathrm{kDa}$ fatty acid-binding recombinant protein. Parasite Immunol 22: 41-48.

Colley DG, Cook JA, Freeman Jr GL, Bartholomew RK, Jordan P 1977. Immune responses during human schistosomiasis mansoni. I. In vitro lymphocyte blastogenic responses to heterogeneous antigenic preparations from schistosome eggs, worms and cercariae. Int Arch Allergy Appl Immunol 53: 420-433.

Correa-Oliveira R, Pearce EJ, Oliveira GC, Golgher DB, Katz N, Bahia LG, Carvalho OS, Gazzinelli G, Sher A 1989. The human immune response to defined immunogens of Schistosoma mansoni: elevated antibody levels to paramyosin in stool-negative individuals from two endemic areas in Brazil. Trans R Soc Trop Med Hyg 83: 798-804.

Fonseca CT, Brito CF, Alves JB, Oliveira SC 2004. IL-12 enhances protective immunity in mice engendered by immunization with recombinant $14 \mathrm{kDa}$ Schistosoma mansoni fatty acid-binding protein through an IFN-gamma and TNFalpha dependent pathway. Vaccine 22: 503-510.

Harder A 2002. Chemotherapeutic approaches to schistosomes: current knowledge and outlook. Parasitol Res 88: 395-397.

Lanar DE, Pearce EJ, James SL, Sher A 1986. Identification of paramyosin as schistosome antigen recognized by intradermally vaccinated mice. Science 234: 593-596.

Moser D, Tendler M, Griffiths G, Klinkert MQ 1991. A 14$\mathrm{kDa}$ Schistosoma mansoni polypeptide is homologous to a gene family of fatty acid binding proteins. J Biol Chem 266 : 8447-8454.

Nara T, Tanabe K 1997. The B-cell epitope of paramyosin recognized by a protective monoclonal IgE antibody to Schistosoma mansoni. Vaccine 15: 79-84.

Pearce EJ, James SL, Hieny S, Lanar DE, Sher A 1988. Induction of protective immunity against Schistosoma mansoni by vaccination with schistosome paramyosin (Sm97), a nonsurface parasite antigen. Proc Natl Acad Sci USA 85: 5678-5682.

Ribeiro de Jesus A, Araujo I, Bacellar O, Magalhaes A, Pearce E, Harn D, Strand M, Carvalho EM 2000. Human immune responses to Schistosoma mansoni vaccine candidate antigens. Infect Immun 68: 2797-2803.

Tallima H, Montash M, Veprek P, Velek J, Jezek J, El Ridi R 2003. Differences in immunogenicity and vaccine potential of peptides from Schistosoma mansoni glyceraldehyde 3phosphate dehydrogenase. Vaccine 21: 3290-3300.

Tarrab-Hazdai R, Schechtman D, Arnon R 1998. Synthesis and characterization of a protective peptide-based vaccine against Schistosoma mansoni. Infect Immun 66: 4526-4530.

Vilar MM, Barrientos F, Almeida M, Thaumaturgo N, Simpson A, Garratt R, Tendler M 2003. An experimental bivalent peptide vaccine against schistosomiasis and fascioliasis. Vaccine 22: 137-144. 